\title{
Thermomagnetic Study of Different Brazilian Geostructural Contexts and Curie Surface Mapping
}

Jesus, B.L. ${ }^{1}$, Guimarães, S.N.P. ${ }^{2}$ and Vieira, F.P. ${ }^{2}$

${ }_{1}^{1}$ Department of Geology and Geophysics, University Federal Fluminense (DGG/UFF)

${ }^{2}$ Department of Geophysics, National Observatory (ON/MCTI)

Copyright 2021, SBGf - Sociedade Brasileira de Geofísica.

This paper was prepared for presentation during the $17^{\text {th }}$ International Congress of the Brazilian Geophysical Society held in Rio de Janeiro, Brazil, 16-19 August 2021.

Contents of this paper were reviewed by the Technical Committee of the $17^{\text {th }}$ International Congress of the Brazilian Geophysical Society and do not necessarily represent any position of the SBGf, its officers or members. Electronic reproduction or storage of any part of this paper for commercial purposes without the written consent of the Brazilian Geophysical Society is prohibited.

\section{Abstract}

The Brazilian geological setting, in the crust, has the potential to contain important minerals, oil and geothermal resources. Crustal structural provinces are segments of the lithosphere that have the same range of geochronological ages and similar thermogeological histories.

Fault or shear zones, non-conformities or rapid changes can mark the boundaries between these provinces to the metamorphic degree or by intrusive contacts. The study of the thermal structure of the crust that characterizes the upper lithospheric layer allows the knowledge of this great potential of the country that remains unknown due to limited exploratory research.

Thus, a possibility of crustal thermal modeling is based on the use of aeromagnetic data to estimate the depth of the Curie Surface (CS) to assess the potential for geothermal exploration. The CS is an isothermal surface on which the magnetic minerals lose their magnetization and, as such, delineate an isotherm around $580^{\circ} \mathrm{C}$ (Curie temperature of the magnetite). We used spectral analysis technique in these data to estimate the depth of the layer related to the deep sources of the crust and its spatial distribution and to compare our findings with geothermal fields known as direct modeling.

\section{Results and Conclusion}

For the construction of the Curie grid, 236 spectral windows ranging from $100-500 \mathrm{~km}$ were selected, which allowed regular sampling of $2 \times 2$ degrees with the curie information located in the center of the windows. The result of this distribution is illustrated in Figure (1). The centroid model brought information from three deep magnetized layers into the crust, which are separated by types of sources: shallow $\left(z_{\text {mean }}=3.6 \mathrm{~km}\right)$, intermediate $\left(z_{\text {mean }}=7.6 \mathrm{~km}\right)$ and deep $\left(z_{\text {mean }}=29.5 \mathrm{~km}\right)$. Thus, the average depth of the Curie Surface for the entire national territory varies by about $31.2 \mathrm{~km}$, the differentiation occurs in the different structural provinces allowing its thermal history associated with the most diverse Tectono-evolutionary processes.

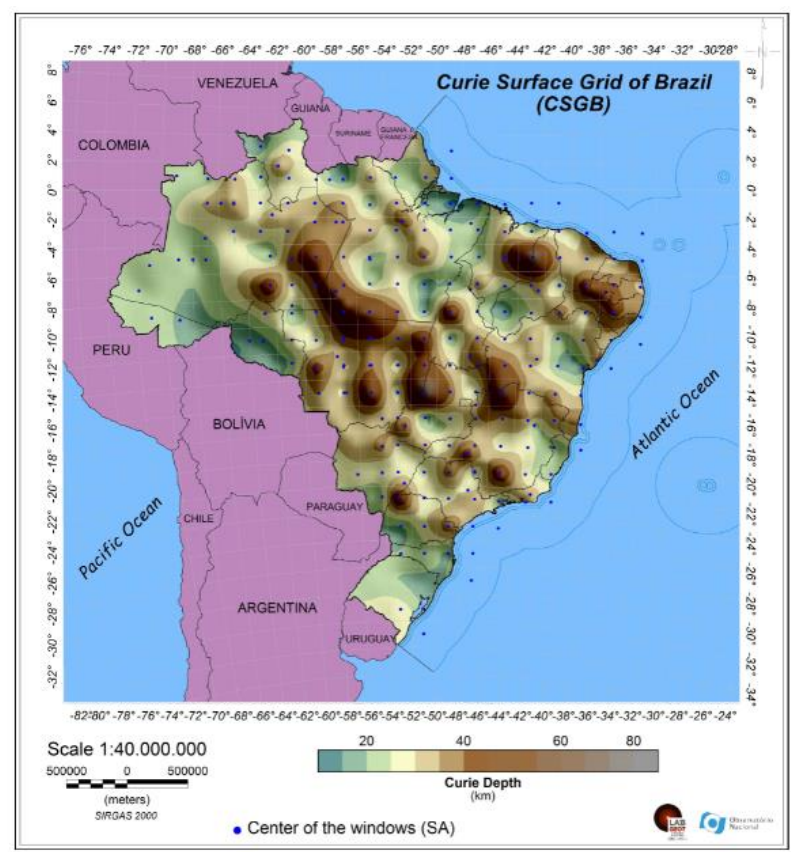

Figure (1) - Curie Surface Grid of Brazil (CSGB) using spectral analysis of the aeromagnetic data. 